\title{
Investigation of Opening Positions on the Natural Ventilation in a Low-Rise Building by CFD Analysis
}

\author{
Sherzad Hawendi, Shian Gao \\ Engineering Department, University of Leicester \\ University Road, Leicester, UK \\ sh567@le.ac.uk; sg32@le.ac.uk
}

\begin{abstract}
A three dimensional computational fluid dynamics (CFD) simulation of coupled outdoor wind flow and indoor air flow is presented to investigate the effective parameters on cross ventilation and flow patterns inside an isolated house. Different opening positions are used to investigate the effect position of opening on the flow patterns inside the building. The study employed the low Reynolds number (LRNM) with Steady Reynolds Averaged Navier -Stokes (RANS) RNG k-e modelling approaches in the simulation. The CFD simulation is validated based on detailed wind tunnel experiments. The study showed that the efficiency of natural ventilation can be increased by following the behaviour of flow stream inside the house and controlling the recirculation areas which are formed in different rooms.
\end{abstract}

Keywords: Computational fluid dynamics, Cross ventilation, Isolated house, RNG k-e modelling

\section{Introduction}

Building ventilation plays an important role in supplying good air quality and thermal comfort inside buildings for residents, and can be achieved by regulating indoor parameters, such as air speed, temperature, relative humidity. In addition, it has an important factor in the development of sustainable sector. Natural ventilation depends on natural driving forces, such as wind and buoyancy forces, to provide fresh air to inside buildings. Regarding natural ventilation, it can be difficult to maintain the conditions inside a building in a stable state because the weather outside often changes. Larson and Heiselberg [1] mentioned some requirements which should be set for this type of ventilation due to limited natural driving forces such as internal heat load in the building, depth of the room, room height, and surroundings. Natural ventilation can be divided into two categories denoting the position of the openings in the outer walls: single-side ventilation and cross ventilation. In single-side ventilation, the air interchanges by wind or buoyancy effect through large natural ventilation openings (such as windows or doors) and the openings in one wall. Cross ventilation is generated by the action of any wind from multiple openings on different facades of the room, and the air crosses the room because of the gradient in pressure.

Previous experimental studies of natural ventilation can be divided into two types, reduced scale experimental models and full-scale models, and many types of buildings have been tested for numerous reasons. Ernest, et al. [2] compared ventilation rates between open and sealed models by using surface pressure distribution, and showed satisfactory correlation when a small aperture is used with normal direction of wind to the aperture. The test showed that ventilation rate decreases with non-normal wind direction. Kato, et al. [3] investigated the mechanisms of cross ventilation with open windows, by analysing in detail velocity and pressure fields of airflow in and around buildings. Straw [4] used a cube (6m) with two apertures in open landscape to evaluate the tracer gas method and calculation methods from orifice expression equation against calculation from measured velocity profile in the openings. Later, Yang [5] used the same cube to study both wind driven and buoyancy driven cross ventilation under various weather conditions in England. The field measurements data was valuable for comparison with small-scale wind tunnel results and validation of CFD simulation.

CFD has been widely used in predicting ventilation performance because of the rapid increase in computer capacity and the development of the CFD program. Reynolds Averaged Navier-Stokes (RANS) and Large Eddy Simulation (LES) are mainly used in turbulence modelling. Chen [6] mentioned that many researchers have concluded that RANS could perform well for one flow but poorly in another, and the performance of the RNG k- $\varepsilon$ model was relatively stable while the performance of the LES was more satisfactory and obtained good agreement with measured results in several studies [7],[8],[9] and [10]. 
Kindangen, et al. [11] predicted the impact of wind direction, roof height and shape, and building overhang on the flow distribution inside buildings using a standard k- $\varepsilon$ model. The same turbulence model is used by Elmualim and Awbi [12] to show the performance of speed and direction of wind on the ventilation system based on the wind catcher design. The standard $\mathrm{k}-\varepsilon$ turbulence model is used to predict the flow distribution in and around a single room with dimension $(3 \times 3 \times 2.4 \mathrm{~m})$. Evola and Popov [13] showed that the RNG k- $\varepsilon$ model is more accurate than the standard k- $\varepsilon$ model in predicting the cross ventilation, single-side for both windward and leeward opening. Stavrakakis, et al. [14] applied three k- $\varepsilon$ turbulent models: standard, RNG, and realizable, to study natural ventilation by wind and buoyancy effect of a building. The performance of the RNG model was relatively better, particularly for the purpose of temperature prediction, and suggested that it should be used for thermal comfort estimation applications.

Ramponi and Blocken [15] used Particle Image Velocimetry (PIV) to validate the 3D steady Reynolds-Averaged Navier-Stocks (RANS) approach with the SST k-w model for four different building configurations. Their study includes the impact of changing the inlet profiles of turbulent kinetic energy and effect by applying both first-order and secondorder discretization schemes. Ai and Mak [16] performed a comparison study against field measurements to evaluate the single-sided ventilation rate in a multi-story building using three methods: the renormalization (RNG) k- $\varepsilon$ turbulence model, integration method and Tracer gas decay method. Their study demonstrates that CFD simulation is more suitable for the determination of ventilation rate in multi-storey buildings, particularly in the design stage.

One of the most challenging aspect of building design is position and shape (shape parameter not included in this report) of the openings. These parameters not only change the appearance of the building greatly but could also strongly influence the efficiency of natural ventilation. Although importance of openings position in buildings, there are not enough studies which focus on their influence on natural ventilation especially complex geometry such as houses. The main focus of the present study is to investigate the effect of the position of openings on natural cross ventilation using numerical simulation. Steady RANS method is used to simulate the problem and low Reynolds number modelling (LRNM) is used to model the boundary-layer region for reason of improved accuracy.

\section{Numerical Method}

Computational fluid dynamics is based on the resolution of the governing equations which describe the flow field in the computational domain. The governing equations describing air flow consist of continuity, momentum and turbulent modelling equations. The continuity equation can be written as follows:

$$
\nabla \cdot\left(\rho u_{i}\right)=0
$$

while, conversation of momentum is written in the form:

$$
\frac{\partial\left(\rho u_{j} u_{i}\right)}{\partial x_{j}}=-\frac{\partial p}{\partial x_{i}}+\frac{\partial}{\partial x_{i}}\left\{\mu\left(\frac{\partial u_{i}}{\partial x_{i}}+\frac{\partial u_{i}}{\partial x_{i}}\right)\right\}
$$

The Renormalization Group (RNG) model is chosen over the other variants of the two equation turbulence models because of its popularity for modelling indoor air movement [13]. It is based on the standard model (k-e) and modified by Yakhot, et al[17]. The modelled transport equations for $\mathrm{k}$ and $\varepsilon$ in the renormalization $\mathrm{k}-\varepsilon$ model are:

$$
\begin{gathered}
\frac{\partial}{\partial x_{i}}\left(\rho k u_{i}\right)=\frac{\partial}{\partial x_{j}}\left[\left(\mu+\frac{\mu_{t}}{\sigma_{k}}\right) \frac{\partial k}{\partial x_{j}}\right]+P_{k}-\rho \varepsilon \\
\frac{\partial}{\partial x_{j}}\left(\rho \varepsilon u_{i}\right)=\frac{\partial}{\partial x_{j}}\left[\left(\mu+\frac{\mu_{t}}{\sigma_{\varepsilon}}\right) \frac{\partial \varepsilon}{\partial x_{j}}\right]+C_{1 \varepsilon} \frac{\varepsilon}{k} P_{k}-C_{2 \varepsilon}^{*} \rho \frac{\varepsilon^{2}}{k}
\end{gathered}
$$

where $C_{2 \varepsilon}^{*}=C_{2 \varepsilon}+\frac{C_{\mu} \eta^{3}\left(1-\frac{\eta}{\eta_{0}}\right)}{1+\beta \eta^{3}}, \quad \eta=S \frac{k}{\varepsilon}, \quad S=\sqrt{2 S_{i j} S_{i j}} \quad, C_{2 \varepsilon}=1.68, C_{1 \varepsilon}=1.44$ 


\section{Model and Cases}

The basic configuration of the studied model was an isolated house with height $\mathrm{H}$ in cross turbulent flow with two square openings $(0.2 \mathrm{H})$ at the front wall and two openings at rear side of the house. The dimension of the house is $(3.33 \times 1 \times 2.66) \mathrm{H}$ and wall porosity is 0.03 . The position of the two openings is changed according to the cases as shown in Fig.1. The external wind speed was set at $U_{\text {ref }}=7 \mathrm{~m} / \mathrm{s}$ and wind direction is normal on the front side of the house. In all cases Reynolds number is constant based on height of building and equal to $13.9 \times 10^{3}$.

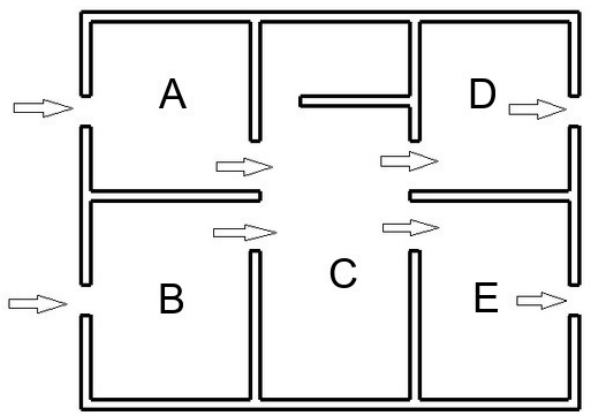

(a)

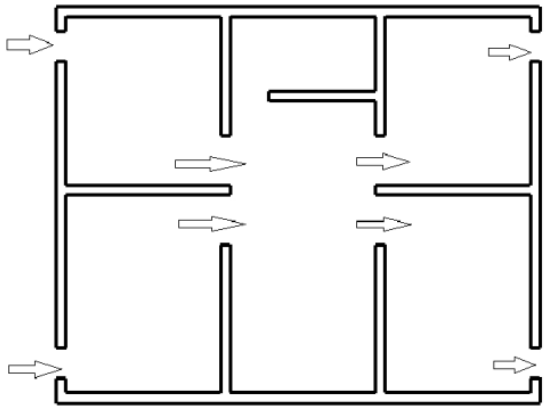

(b)

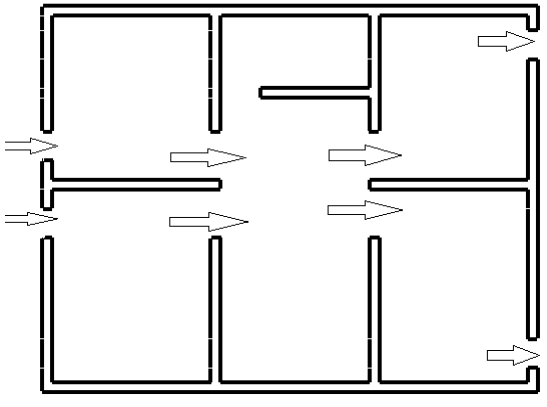

(c)

Fig.1: Schematic of cases used for investigating opening positions. (a) case I, (b) case II, and (c) case III.

\section{Computational Domain and Grid}

A 3-D computational domain is based on the COST [18] and AIJ [19] guidelines. It consists of a rectangular house with height $\mathrm{H}$ inside a duct $(33.3 \times 5 \times 7.6) \mathrm{H}$ as shown in Fig.2. The blockage ratio is $4.2 \%$ which is smaller than that recommended in the guidelines.
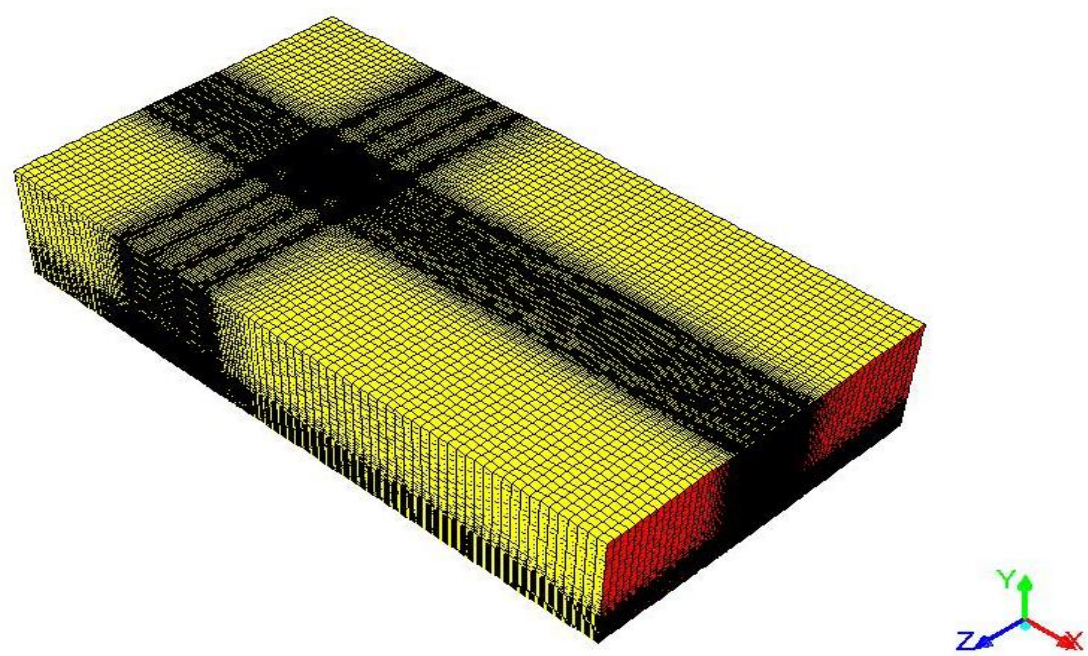

Fig. 2: Computational domain.

ICEM was used to generate the three dimensional grid and hexahedral cells were used inside the domain. A fine mesh was structured near the walls because LRNM grids require a high cell density, while coarse mesh was used away from the walls in all directions. The space between the walls of the house and the centre of the first cell was $0.0066 \mathrm{H}$ and the same distance was used for ground, which is small enough to get $\mathrm{y}^{+}$small than 5 as suggested by Blocken, et al. [20]. Grid independence is an important factor in numerical simulation, in order to find the effect of mesh size on the results. Three models of grid size were chosen G1 $\left(1.5 \times 10^{6}\right)$, G2 $\left(3.5 \times 10^{6}\right)$ and G3 $\left(5.5 \times 10^{6}\right)$, with the refinement ratio between (G1 and G2) and (G2 and G3) at around 1.5 in each dimension which is recommended by Stern, et al. [21]. The ventilation 
rate of the two openings was used to validate the grid size sensitivity. To minimize the long computational time the medium grid G2 is a good compromise between the coarse and fine grid size.

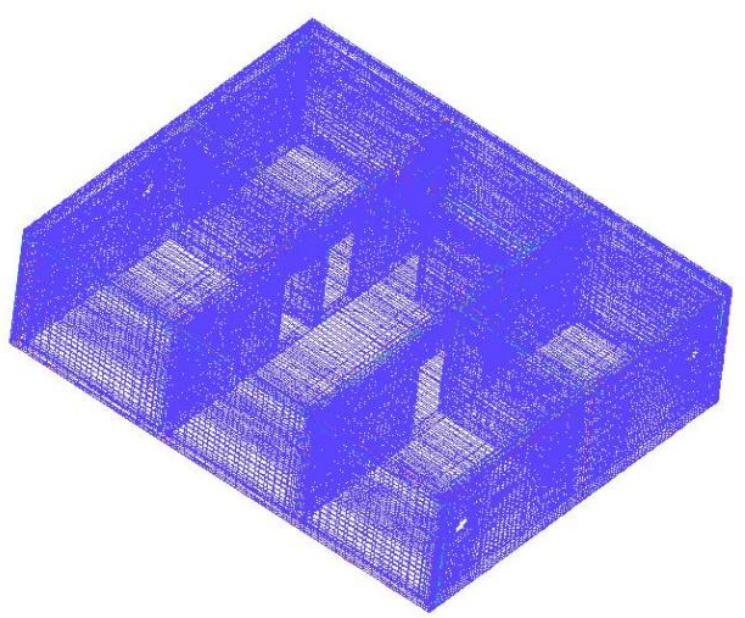

Fig. 3: Grid distribution of the building model.

The boundary conditions play an important role in the results and the effect of the surroundings can be represented. According to Richards and Hoxey [22], the vertical profiles of the mean wind velocity, turbulent kinetic energy and turbulent dissipation rate are imposed at the inlet of the domain. The equations used for the profiles are:

$$
\begin{aligned}
U(y) & =\frac{u_{\tau}}{K} \ln \left(\frac{y+y_{o}}{y_{o}}\right) \\
k & =1.5(\mathrm{U} \mathrm{I})^{2} \\
\varepsilon & =\frac{u_{\tau}^{3}}{K\left(y+y_{o}\right)}
\end{aligned}
$$
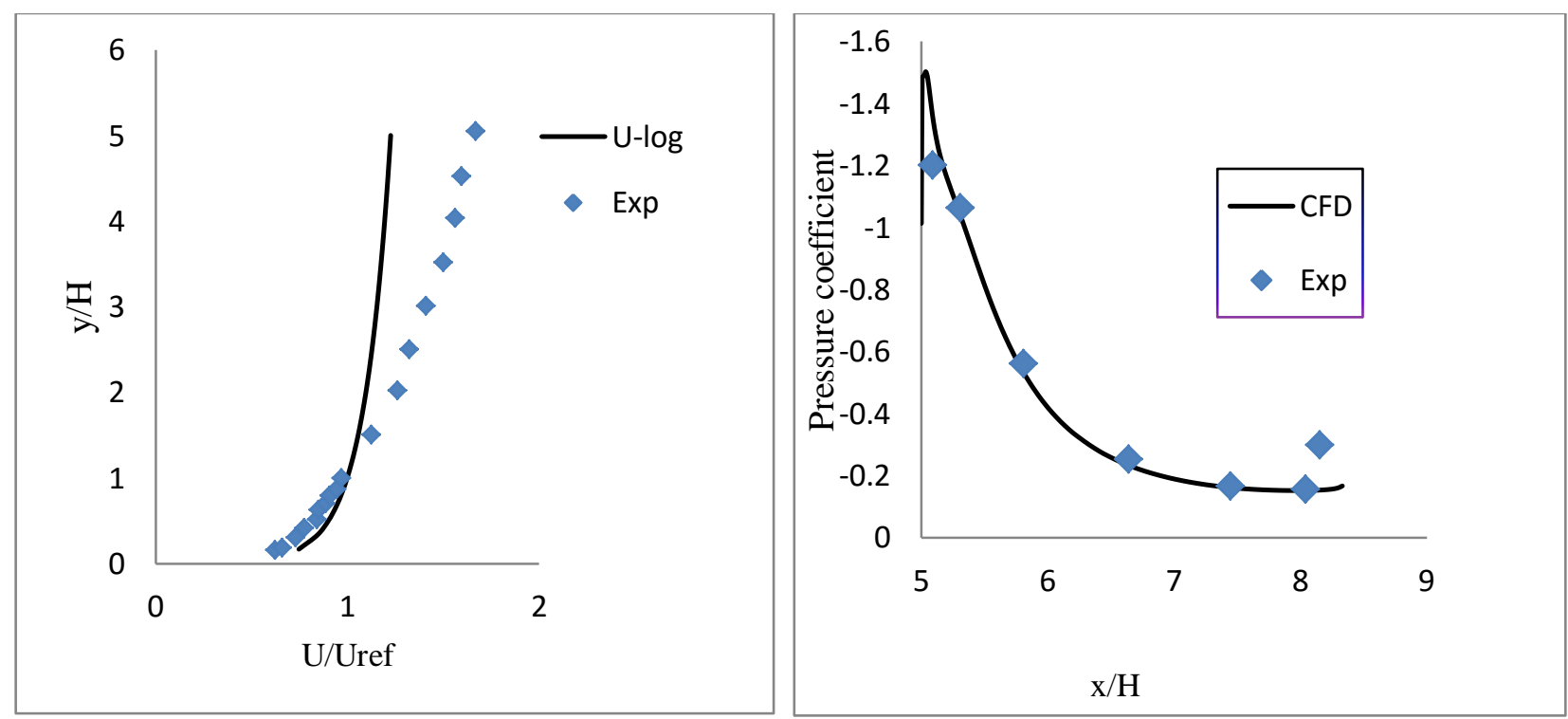

Fig. 4: Mean velocity profile at inlet and centreline pressure coefficient for the top of the house (CFD vs experiment).

The lateral and the top of the domain are modelled as symmetry conditions, i.e. zero normal velocity and normal gradients of all variables. The ground of the domain modelled as a no-slip boundary is assumed, and zero surface 
roughness should be used in LRNM [22]. At the outlet of the domain, zero static pressure is used. The surfaces of the house are assumed as no-slip boundaries.

\section{Model Verification}

In order to prove the accuracy of the CFD simulation, the flow field and pressure coefficients at the top surfaces of building for the third case was compared with the wind tunnel experiment of Ohba et al. [23]. The approaching flow is turbulent boundary layer and the velocity profile $\mathrm{U}(\mathrm{y})$ follows the logarithm law velocity (eq.5). The vertical profile of time-averaged velocity $\mathrm{U}(\mathrm{y})$ is shown in Fig 4, and the solid symbols are the experiment of Ohba et al. [23]. In spite of the simulation velocities deviated from the measured velocities near the inlet, the agreement between numerical and experimental results at the level of building was satisfactory. Fig. 4 compares the simulation pressure coefficients at the centrelines of building facades with the wind tunnel results and showed a good agreement.

\section{Results and Discussion}

In this section three different positions in three cases were studied in order to provide information about the effect of opening positions on flow pattern and recirculation areas in the low-rise building. In these cases two openings are located in two opposite side of the building which are called inlet (windward side) and outer (leeward side). A high pressure zone is created on the windward side of the building whereas a low pressure zone is formed on the rear side and the flow through the building mainly driven by this pressure difference. Geometry of this study can be considered as five rooms named A, B, C, D and E as shown Fig. 1a. The flow pattern and recirculation zones in each room will be discussed thoroughly in the following sections to provide helpful information for effective design of buildings.

In each room there are recirculation zones formed mainly in rooms A and B with flow entering the house directly by the two openings, while the recirculation is weaker in rooms D and E. In the rooms A and B of case I (Fig. 5.a) the recirculation area is divided into two small zones while in case II and III there is only one zone. All recirculation zones inside rooms of case I are slightly weaker than other cases except for room C. Therefore the case I is more comfortable than other cases and this is because the opening position lies in med of the wall. In addition, the amount of ventilation rate in case I is higher than case II and slightly smaller than case III. Because the room A is smaller than B the results of all cases showed that the recirculation zones in this room are stronger than room $\mathrm{B}$. The results showed that in each case there is a room which is more discomfort than other rooms, for example in case I room C while room A in case II and case III. In addition the results prove that rooms $\mathrm{D}$ and $\mathrm{E}$ are more comfort than other rooms in all cases and there is no significant difference between these cases. Comparison of openings aerating flow can be very important for designers who want to design houses with high ventilation efficiency. Figure 6 summarized three cases included in this study and represents their flow rate obtained from the CFD simulation. It can be seen that cases I and III have maximum flow rate.

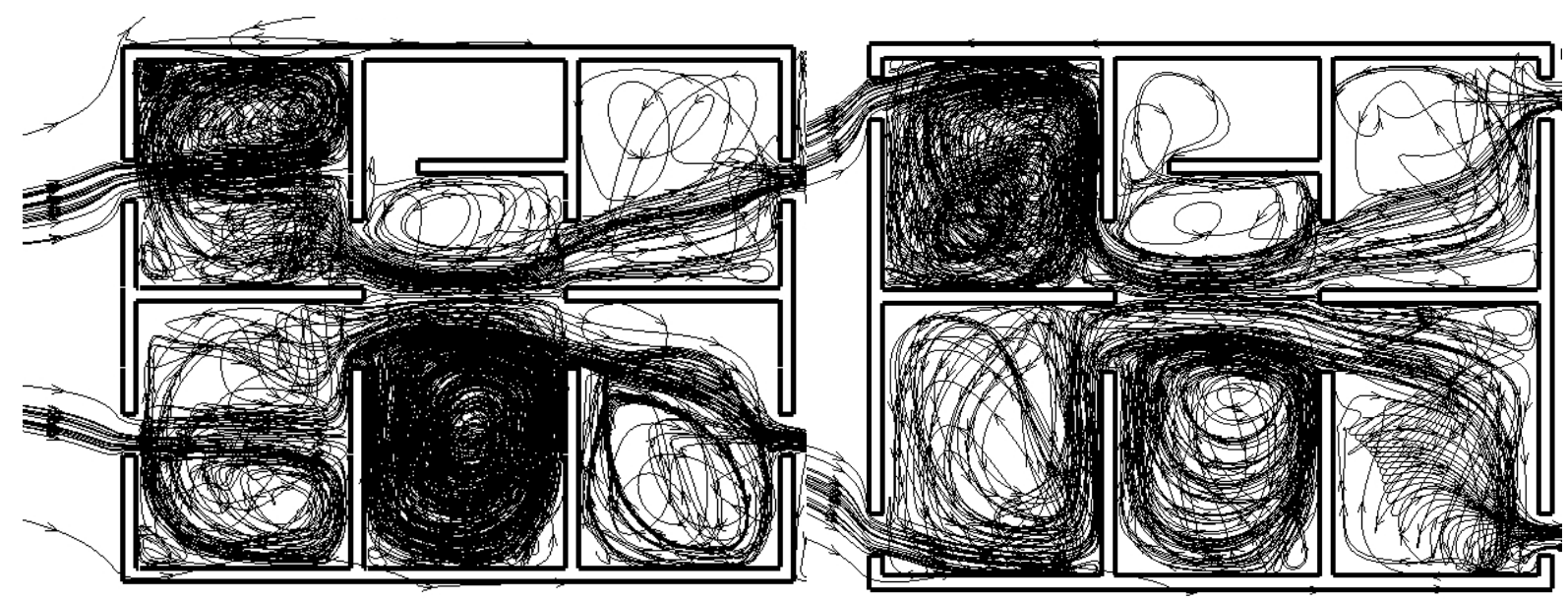

(a)

(b) 


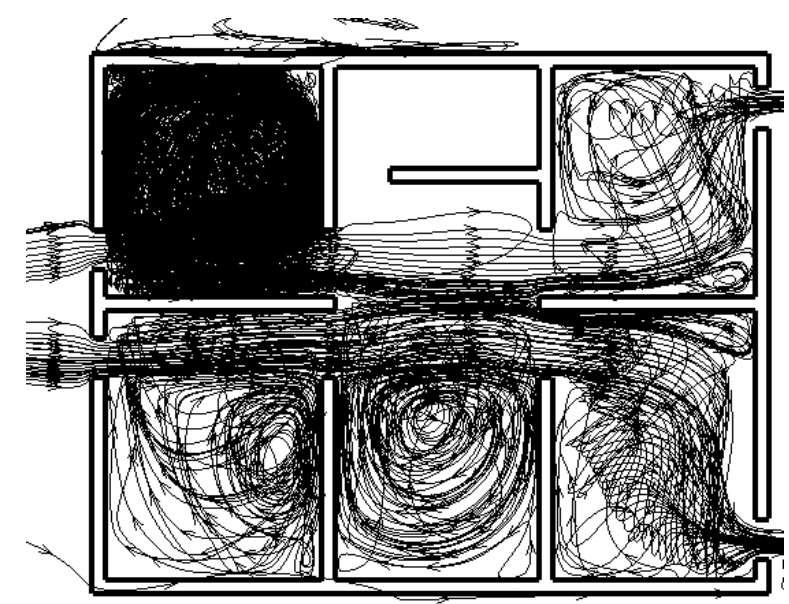

(c)

Fig. 5: Stream line of induced flow inside the building. (a) case I, (b) case II, and (c) case III.

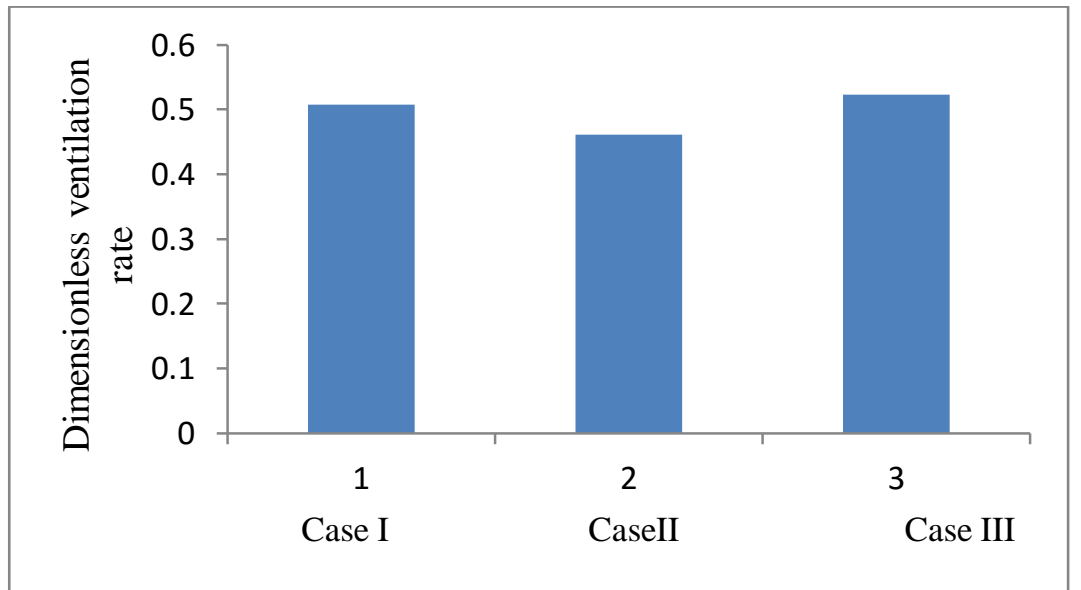

Fig. 6: Comparison of dimensionless ventilation rate for each case.

\section{Conclusion}

In this project, natural cross-ventilation in a low-rise building has been investigated by using CFD simulation techniques. Steady RANS models are performed and the numerical results are validated with available experimental data. It is found that the building openings are important factors in design and can significantly affect the air stream patterns inside the building. Based on the CFD results it showed that a strong recirculation is formed in rooms A and B and a weaker recirculation is formed in rooms $\mathrm{D}$ and $\mathrm{E}$.

\section{Acknowledgements} appreciated.

The financial support from the Ministry of Higher Education and Scientific Research of Iraq is gratefully

\section{References}

[1] T.S. Larsen, P. Heiselberg, "Single-sided natural ventilation driven by wind pressure and temperature difference," Energy and Buildings, vol. 40, no. 6, pp. 1031-1040, 2008.

[2] D. Ernest, F. Bauman, and E. Arens, "The effects of external wind pressure distributions on wind-induced air motion inside buildings," Journal of Wind Engineering and Industrial Aerodynamics, vol. 44, no. 1, pp. 2539-2550, 1992. 
[3] S. Kato, S. Murakami, A. Mochida, S. I. Akabayashi, and Y. Tominaga, "Velocity-pressure field of cross ventilation with open windows analyzed by wind tunnel and numerical simulation," Journal of Wind Engineering and Industrial Aerodynamics, vol. 44, no. 1, pp. 2575-2586, 1992.

[4] M.P. Straw, "Computation and measurement of wind induced ventilation," University of Nottingham, 2000.

[5] T. Yang, "CFD and field testing of a naturally ventilated full-scale building," University of Nottingham, 2004.

[6] C.R. Chu, Y. H. Chiu, and Y. W. Wang, "An experimental study of wind-driven cross ventilation in partitioned buildings, Energy and Buildings," vol. 42, no. 5, pp. 667-673, 2010.

[7] Y. Jiang and Q. Chen, "Study of natural ventilation in buildings by large eddy simulation," Journal of wind engineering and industrial aerodynamics, vol. 89, no. 13, pp. 1155-1178, 2001.

[8] Y. Jiang, D. Alexander, H. Jenkins, R. Arthur, and Q. Chen, "Natural ventilation in buildings: measurement in a wind tunnel and numerical simulation with large-eddy simulation," Journal of Wind Engineering and Industrial Aerodynamics, vol. 91, no. 3, pp. 331-353, 2003.

[9] C. H. Hu, M. Ohba, and R. Yoshie, "CFD modelling of unsteady cross ventilation flows using LES," Journal of Wind Engineering and Industrial Aerodynamics, vol. 96, no. 10, pp. 1692-1706, 2008.

[10] C. R. Chu, B. F. Chiang, "Wind-driven cross ventilation in long buildings, Building and Environment," vol. 80, pp. 150-158, 2014.

[11] J. Kindangen, G. Krauss, and P. Depecker, "Effects of roof shapes on wind-induced air motion inside buildings, Building and Environment," vol. 32, no. 1, pp. 1-11, 1997.

[12] A.A. Elmualim and H.B. Awbi, "Wind tunnel and CFD investigation of the performance of 'Windcatcher' ventilation systems," International Journal of Ventilation, vol. 1, no. 1, pp. 53-64, 2002.

[13] G. Evola and V. Popov, "Computational analysis of wind driven natural ventilation in buildings," Energy and buildings, vol. 38, no. 5, pp. 491-501, 2006.

[14] G. Stavrakakis, M. Koukou, M.G. Vrachopoulos, and N. Markatos, "Natural cross-ventilation in buildings: Buildingscale experiments, numerical simulation and thermal comfort evaluation," Energy and Buildings, vol. 40, no. 9, pp. 1666-1681, 2008.

[15] R. Ramponi and B. Blocken, "CFD simulation of cross-ventilation flow for different isolated building configurations: validation with wind tunnel measurements and analysis of physical and numerical diffusion effects," Journal of Wind Engineering and Industrial Aerodynamics, vol. 104, pp. 408-418, 2012.

[16] Z. Ai and C. Mak, "Determination of single-sided ventilation rates in multistory buildings: Evaluation of methods," Energy and Buildings, vol. 69, pp. 292-300, 2014.

[17] V. Yakhot, S. A. Orszag, S. Thangam, T. B. Gatski, and C. G. Speziale, "Development of turbulence models for shear flows by a double expansion technique," Physics of Fluids A, vol. 4, no. 7, pp. 1510-1520, 1992.

[18] J. Franke, A. Hellsten, K. H. Schlunzen, and B. Carissimo, "The COST 732 Best Practice Guideline for CFD simulation of flows in the urban environment: a summary," International Journal of Environment and Pollution, vol. 44, no. 1-4, pp. 419-427, 2011.

[19] Y. Tominaga, A. Mochida, R. Yoshie, H. Kataoka, T. Nozu, M. Yoshikawa, and T. Shirasawa, "AIJ guidelines for practical applications of CFD to pedestrian wind environment around buildings," Journal of wind engineering and industrial aerodynamics, vol. 96, no. 10, pp. 1749-1761, 2008.

[20] T. Defraeye, B. Blocken, J. Carmeliet, "CFD analysis of convective heat transfer at the surfaces of a cube immersed in a turbulent boundary layer," International Journal of Heat and Mass Transfer, vol. 53, no. 1, pp. 297-308, 2010.

[21] F. Stern, R.V. Wilson, H.W. Coleman, and E.G. Paterson, "Comprehensive approach to verification and validation of CFD simulations-part 1: methodology and procedures," Journal of fluids engineering, vol. 123, no. 4, pp. 793-802, 2001.

[22] P. Richards and R. Hoxey, "Appropriate boundary conditions for computational wind engineering models using the k$\epsilon$ turbulence model," Journal of wind engineering and industrial aerodynamics, vol. 46, pp. 145-153, 1993.

[23] M. Ohba, K. Irie, and T. Kurabuchi, "Study on air flow charactristics inside and outside a cross-ventilation model and ventilatin flow rates using wind tunnel experimental building," Journal of Wind Engineering and Industrial Aerodynamics, vol. 89, pp. 1513-1524, 2001. 